\title{
"COVID-19 em Sarilhos": respostas de intervenção na promoção de competências autorregulatórias em período de pandemia
}

\author{
https://doi.org/10.21814/uminho.ed.24.3
}

\section{Pedro Rosário}

Pedro Rosário (ORCID: 0000-0002-3221-1916) é Professor Associado com agregação do Departamento de Psicologia Aplicada da Universidade do Minho. Concluiu o doutoramento em Psicologia da Educação na mesma instituição e tem centrado a sua investigação na autorregulação da aprendizagem e no envolvimento escolar.

\section{Jennifer Cunha}

Jennifer Cunha (ORCID: 0000-0001-8604-2049) é investigadora do Centro de Investigação em Psicologia (CIPSI) da Escola de Psicologia da Universidade do Minho, onde concluiu o doutoramento em 2018.

\section{Armanda Pereira}

Armanda Pereira (ORCID: 0000-0001-5009-8980) é investigadora do Centro de Investigação em Psicologia (CIPSI) da Escola de Psicologia da Universidade do Minho, onde concluiu o doutoramento em 2018.

\section{Ana Guimarães}

Ana Guimarães (ORCID: 0000-0002-8703-7492) é bolseira de investigação do Grupo Universitário de Investigação em Autorregulação, da Escola de Psicologia da Universidade do Minho. 


\section{Clara Vieira}

Clara Vieira (ORCID: 0000-0002-4587-9077) é bolseira de investigação do Grupo Universitário de Investigação em Autorregulação, da Escola de Psicologia da Universidade do Minho.

\section{Dulce Lopes}

Dulce Lopes (ORCID: 0000-0001-7125-5981) é bolseira de investigação do Grupo Universitário de Investigação em Autorregulação, da Escola de Psicologia da Universidade do Minho.

\section{Patrícia Sousa}

Patrícia Sousa (ORCID: 0000-0002-4209-6878) é bolseira de investigação do Grupo Universitário de Investigação em Autorregulação, da Escola de Psicologia da Universidade do Minho. 


\section{INTRODUÇÃO}

A pandemia COVID-19 desarrumou as nossas vidas sem aviso prévio. A chegada repentina trouxe inúmeros desafios pessoais e sociais com impacto significativo na vida das pessoas e dos contextos. As medidas contra a propagação do vírus (e.g., o encerramento das escolas, teletrabalho) trouxeram mudanças significativas para a vida das famílias. Por exemplo, a noção de casa foi resignificada abruptamente. A ideia de casa como lugar de abrigo das famílias, locus privilegiado para o estabelecimento de laços e desenvolvimento pessoal e de lazer em família, incorporou uma componente profissional. Em muitas casas entrou a sala de aula e o escritório sem a necessária preparação. Muitas casas, muitas vidas familiares, converteram-se em escola a tempo inteiro partilhada com escritório(s) profissional(is) trabalhando a tempo inteiro. Esta mudança brusca de práticas sobrecarregou as famílias, já de si preocupadas e ocupadas em responder às exigências sanitárias da pandemia.

Estas mudanças não planificadas colocaram (colocam) desafios diversos à organização e manutenção do bem-estar das famílias; por exemplo, desafios relacionados com a gestão do espaço, do tempo, das tarefas, das expectativas e das emoções dos que coabitam os espaços, entre outros aspetos de relevo. Se a gestão de todas estas dimensões não for orquestrada com a harmonia necessária, a desordem e, eventualmente, o caos podem instalar-se nas vidas das famílias. As consequências negativas são diversas, mas todas concorrem para magoar o bem-estar e dificultar os processos de aprendizagem das crianças e a atividade laboral dos pais.

Os períodos longos de quarentena ou de isolamento social são propícios para manifestar potencialidades e fragilidades dos recursos individuais e coletivos; por exemplo, a autonomia das crianças e a organização das famílias e das instituiçôes. Nestas etapas de estudo e trabalho em casa, a ausência do apoio próximo dos professores e a, muito frequente, acumulação de papéis dos adultos presentes em casa (e.g., pai/cuidador, profissional/professor), num tempo e espaço limitados, são exemplos de fatores (i)mobilizadores. A situação de pandemia veio exigir a todos o exercício musculado de competências de autorregulação, contudo sem préaviso e tempo de adaptação. 
Perante este cenário, o Grupo Universitário de Investigação em Autorregulação (GUIA - http://www.guia-psi.com/), desenvolveu o Projeto "COVID-19 em Sarilhos" com o objetivo de ajudar as famílias portuguesas durante o período de quarentena e isolamento social. Este projeto visa promover competências de autorregulação a partir de um leque alargado e diversificado de propostas (e.g., atividades para desenvolver, estórias e frases para reflexão) disponibilizadas online (via Facebook ${ }^{\circledR} \mathrm{e}$ Instagram ${ }^{\circledR}$, duas das redes sociais mais utilizadas no mundo). No entanto, e cientes de que um número alargado de famílias não tem acesso à internet, o GUIA desenvolveu e ajudou a desenvolver outras modalidades online e offine com o apoio dos seus parceiros (i.e., Fundação Calouste Gulbenkian, Plano Integrado e Inovador de Combate ao Insucesso Escolar da Comunidade Intermunicipal das Terras de Trás-os-Montes, 'MAIS Val - Melhores Aprendizagens, Inovação e Sucesso em Valongo). O projeto "COVID-19 em Sarilhos" nas modalidades online e offline tem origem num projeto anterior designado de "Sarilhos do Amarelo". Este projeto chega a crianças, não apenas de diferentes partes do território nacional, mas também de países e continentes longínquos do nosso. O "Sarilhos do Amarelo" fala diversas línguas e chega a crianças de diversas culturas; todas participam na aventura de incrementar as competências de autorregulação da aprendizagem conduzidas pelo desejo de aprender e de alcançar o seu "Amarelo" (Högemann et al., 2017).

O presente capítulo tem como objetivos apresentar brevemente o projeto spin-off "COVID-19 em Sarilhos", partindo da sua origem ("Sarilhos do Amarelo"), bem como as outras modalidades de intervenção online e offline que surgiram, algumas aprendizagens decorrentes desta experiência e sugestóes para o futuro. 


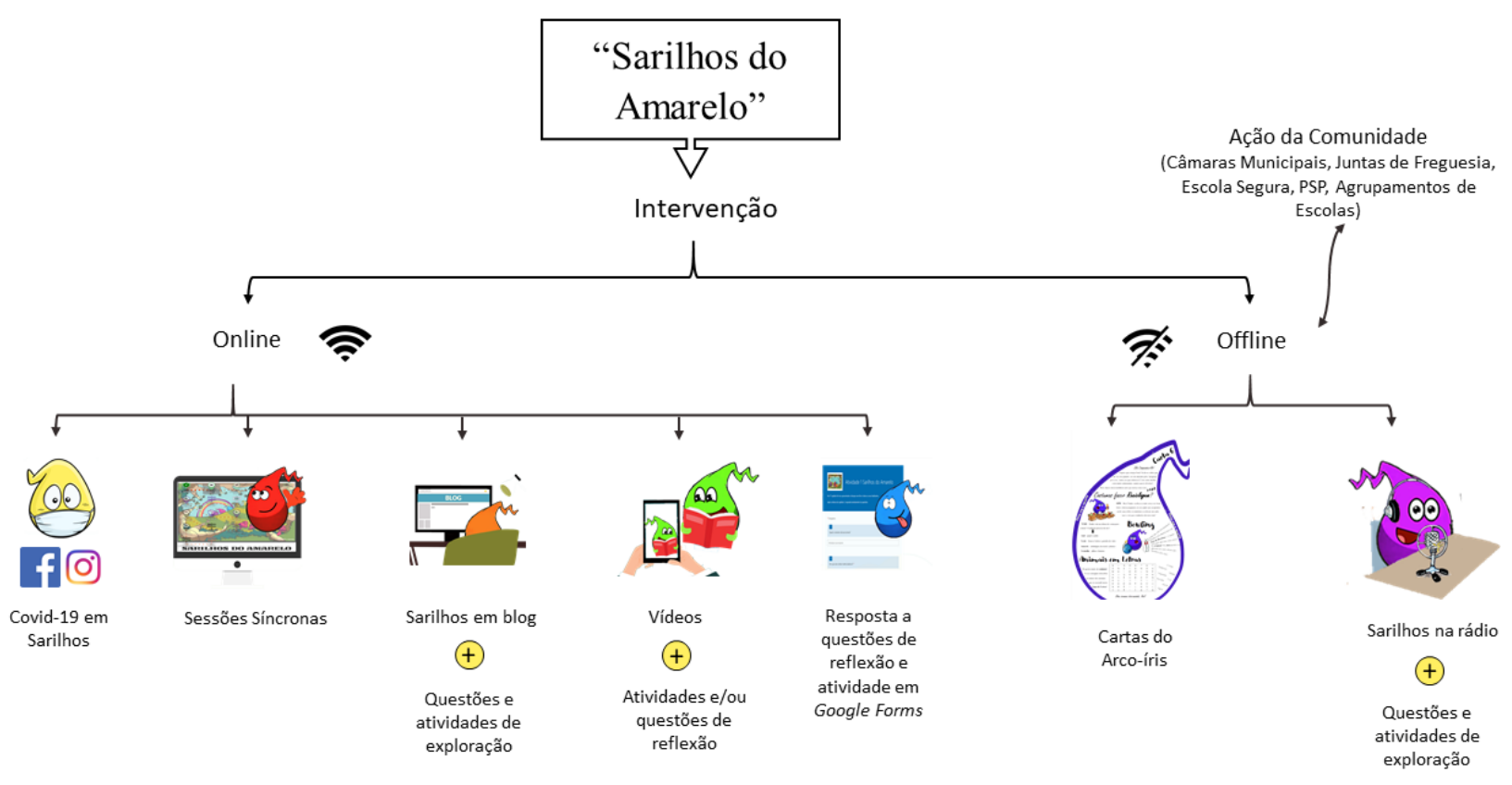

Figura 1. Esquema das diferentes modalidades do projeto.

\section{“SARILHOS DO AMARELO”: DESCRIÇÃO E VALIDAÇÃO}

Rosário e colaboradores desenvolveram, em 2007, um projeto de promoção de competências de autorregulação da aprendizagem a partir da narrativa "Sarilhos do Amarelo”. Esta estória conta as aventuras das cores do arco-íris em busca do seu amigo Amarelo, que se perdeu no bosque (Rosário et al., 2007b) e está fortemente ancorada no valor de que todos somos importantes e, por isso, ninguém pode ficar para trás. Como em qualquer aventura, há desafios e dificuldades a vencer e, para que as cores sejam bem-sucedidas no seu propósito e encontrem o seu amigo, têm de se equipar, aprendendo e aplicando uma série de competências autorregulatórias. Esta estória é a oportunidade para que as crianças adquiram conhecimento declarativo (e.g., o que é planificar), procedimental (e.g., como se planifica) e condicional (e.g., quando e porque se planifica) dos processos e estratégias de autorregulação da aprendizagem. Esta aprendizagem é realizada a partir das experiências das personagens, das reflexôes e atividades desenvolvidas nos e a partir dos capítulos da estória (Rosário et al., 2007a, 2017). Aproveitando as oportunidades que oferecem as aventuras de cada capítulo, as personagens vão ensinando a "pensar antes, durante e depois" de agir, seguindo o modelo 
cíclico PLEA - o acrónimo para PLanificar, Executar e Avaliar (Rosário et al., 2007a, 2017). Concretizando, relativamente à fase de planificação, as crianças aprendem, por exemplo, o que são e como se definem objetivos, bem como a desenhar um plano com estratégias específicas para atingir um determinado objetivo. Aprendem que, na fase de execução, quando colocam o plano em prática, devem monitorizar o processo de ação, por exemplo, analisando a (in)eficácia da estratégia escolhida face ao objetivo previamente definido e efetuando reajustes se necessário. Por fim, aprendem o quão importante é avaliar o resultado final, analisando se correu como previsto e também a refletir nas razóes do (in)sucesso - avaliação que influencia a próxima fase de planificação (e.g., Rosário \& Polydoro, 2014). Assim, este projeto pretende promover a autonomia e agência das crianças (i.e., ação intencional em direção a determinado objetivo, mobilizando os recursos necessários e influenciando o ambiente) no processo de aprender (Bandura, 2006; Rosário et al., 2007a, 2012, 2017).

O trabalho com a referida narrativa, também designada de estória-ferramenta, é implementado por um técnico (e.g., professor, psicólogo) devidamente formado para o efeito pelo GUIA, seguindo a sequência seguinte: montar o cenário (i.e., criar o ambiente para a rotina de trabalho, por exemplo, à mesma hora, os alunos colocam o chapéu amarelo e juntam-se no espaço criado para o efeito), organizador prévio (i.e., revisão dos acontecimentos e aprendizagens anteriores), leitura do(s) capítulo(s), exploração e reflexão do(s) capítulo(s), atividade prática e mensagem para casa/lição final. Habitualmente, a intervenção é realizada em sala de aula, aproximadamente durante cerca de 60 minutos.

A investigação desenvolvida em torno da eficácia da utilização desta ferramenta é vasta. Resultados de teses de mestrado e doutoramento, capítulos de livros académicos e artigos científicos têm evidenciado o impacto positivo de intervenções realizadas com a referida narrativa para incrementar competências autorregulatórias em crianças sub10, bem como as suas crenças de autoeficácia (e.g., Fernandes, 2009; Högemann, 2011, 2016; Rosário et al., 2016). Um estudo mais recente, realizado com crianças de etnia cigana do 4o ano de escolaridade, revelou que a intervenção com a narrativa "Sarilhos do Amarelo" também teve um impacto positivo em medidas concretas de envolvimento comportamental (e.g., pontualidade, participação na aula) e cognitivo (e.g., pedir 
ajuda, verbalizaçóes relativas ao planeamento das tarefas) observadas em contexto de sala de aula (Rosário et al., 2016). Tendo por base o trabalho desenvolvido com a narrativa "Sarilhos do Amarelo", o GUIA construiu o projeto "COVID-19 em Sarilhos" para fazer face aos desafios colocados pelo período de quarentena e de isolamento social que se iniciou em março de 2020.

\section{“COVID-19 EM SARILHOS”: DESCRIÇÃO E ALCANCE}

Uma semana após o encerramento das escolas decretado pelo Estado Português, o GUIA lançou este projeto em duas redes sociais, no Facebook ${ }^{\circledR}$ (COVID-19 em Sarilhos) e no Instagram ${ }^{\circledR}$ (@COVID19_em_sarilhos). Nestas redes foram partilhados vídeos-resumo dos capítulos do "Sarilhos do Amarelo" para os seguidores conhecerem a estória e o processo autorregulatório ensinado através do modelo PLEA. A partir desta etapa, e até ao final do ano letivo (fim de junho), o projeto ofereceu todos os dias sugestóes de atividades patrocinadas pelas cores do arco-íris, cada uma alicerçada em quatro domínios (Figura 2):

- Aprender algo (e.g., aprender diferentes técnicas de desenho, estudar/aprender tabuadas de forma divertida; visitas virtuais a museus),

- Colaborar em casa (e.g., formas expeditas e divertidas para dobrar a roupa, fazer a cama, arrumar a garagem),

- Ajudar alguém (e.g., pistas para poupar recursos e ajudar o planeta, sugestóes para ligar a um amigo para o ajudar nas possíveis dificuldades escolares) e

- Lazer (e.g., sugestôes diversas para realizar exercício físico e jogos familiares). 

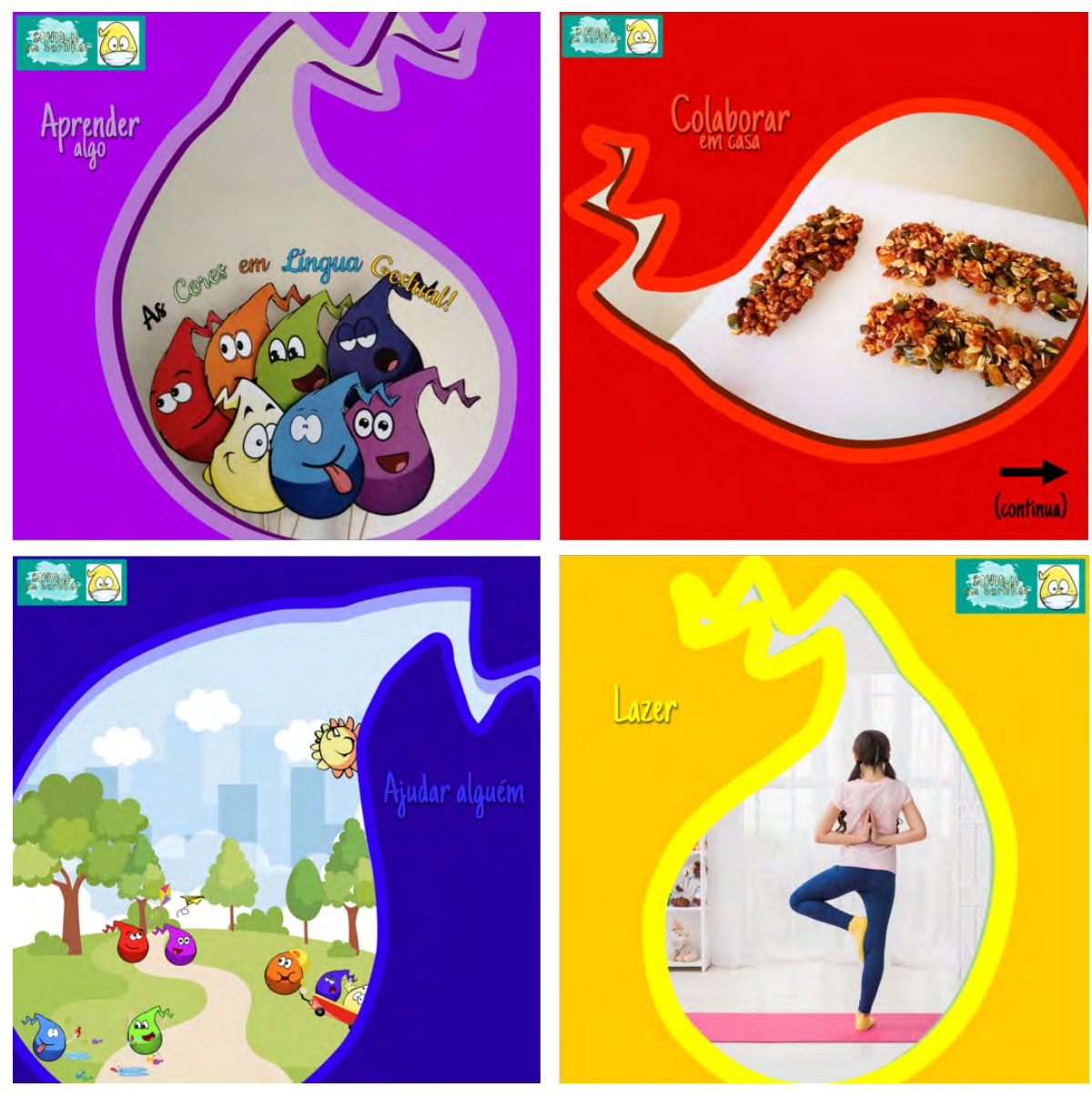

Figura 2. Domínios das atividades disponibilizadas nas páginas do COVID-19 em Sarilhos: "Aprender algo", "Colaborar em casa", "Ajudar alguém” e "Lazer".

Todas as atividades instigam o desenvolvimento de competências autorregulatórias, tal como ilustrado nas figuras 3, 4, 5, 6 .

Os quatro domínios das atividades foram definidos de acordo com as orientaçốes educativas em período de pandemia e com a literatura. A primeira ideia muito importante é que a escola fechou, mas a aprendizagem continua (campanha "School's Out, But Class's On” lançada pelo Ministério da Educação na China, Zhou et al., 2020). Este é o mote para todas as atividades sugeridas no domínio "Aprender algo". Foi muito importante transmitir a mensagem de que o período prolongado de quarentena e isolamento social devido à pandemia (cerca de 4 meses) obrigou a modificar o ritmo e a forma das aprendizagens, mas as crianças não estavam de férias. 


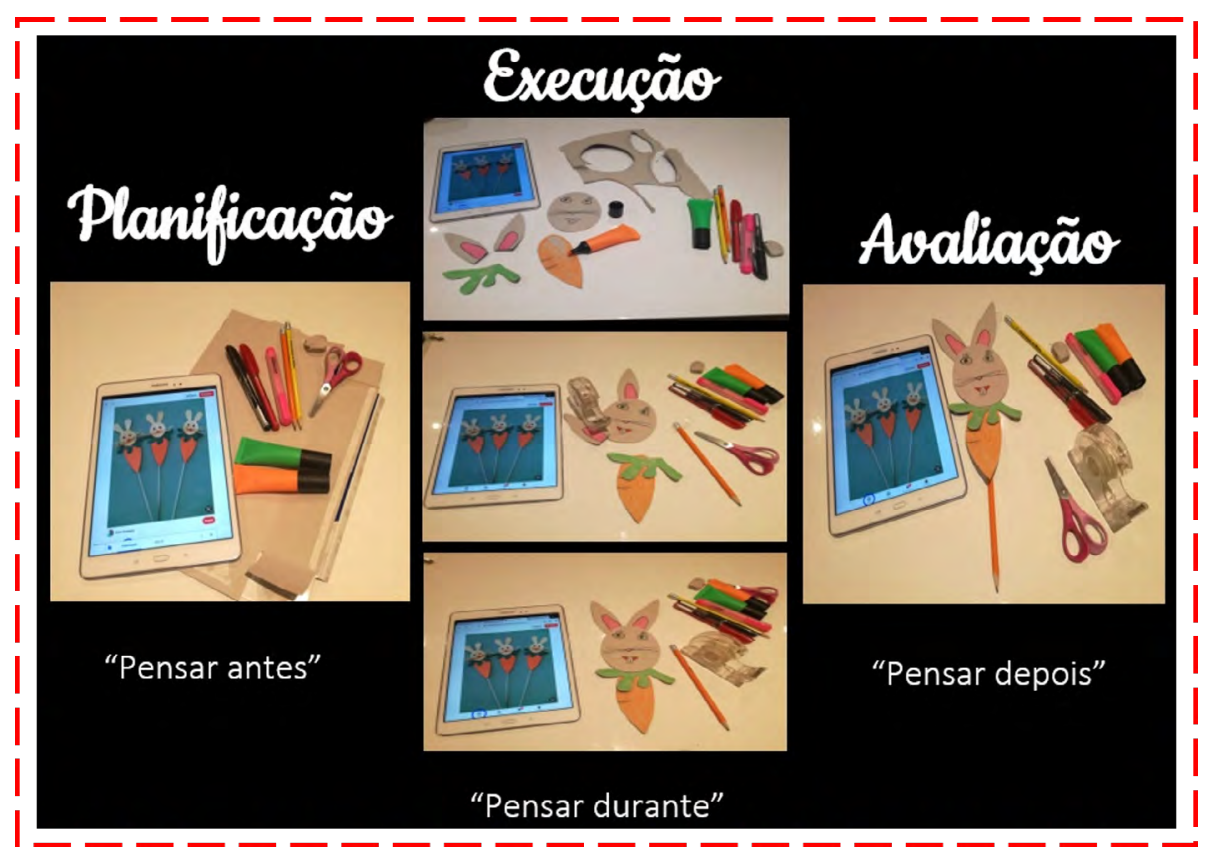

Figura 3. Exemplo de uma atividade do domínio “Aprender algo" (i.e., Aprender a fazer fantoches).

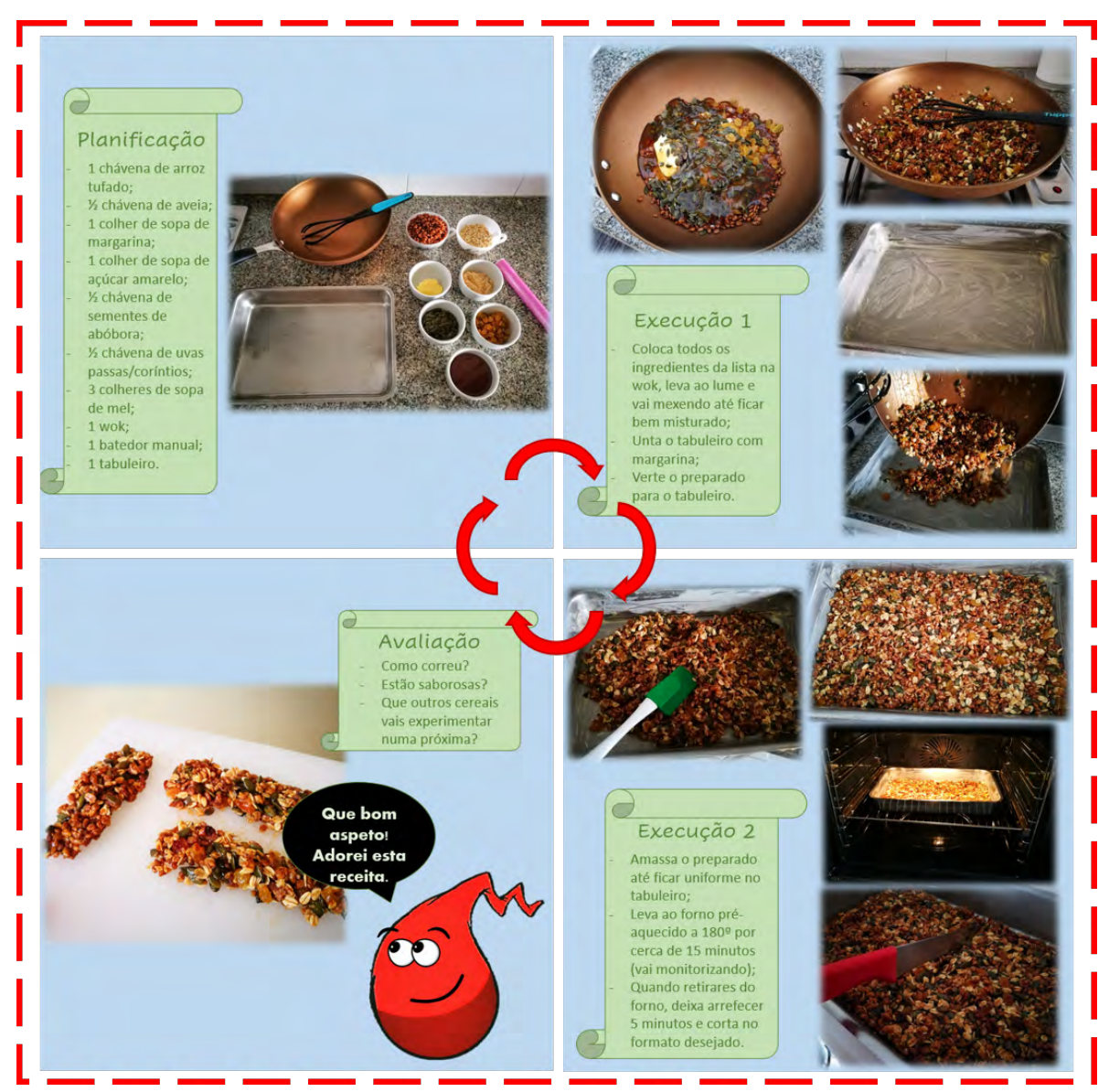

Figura 4. Exemplo de uma atividade do domínio "Colaborar em casa” (i.e., Fazer uma receita para alegrar a família). 


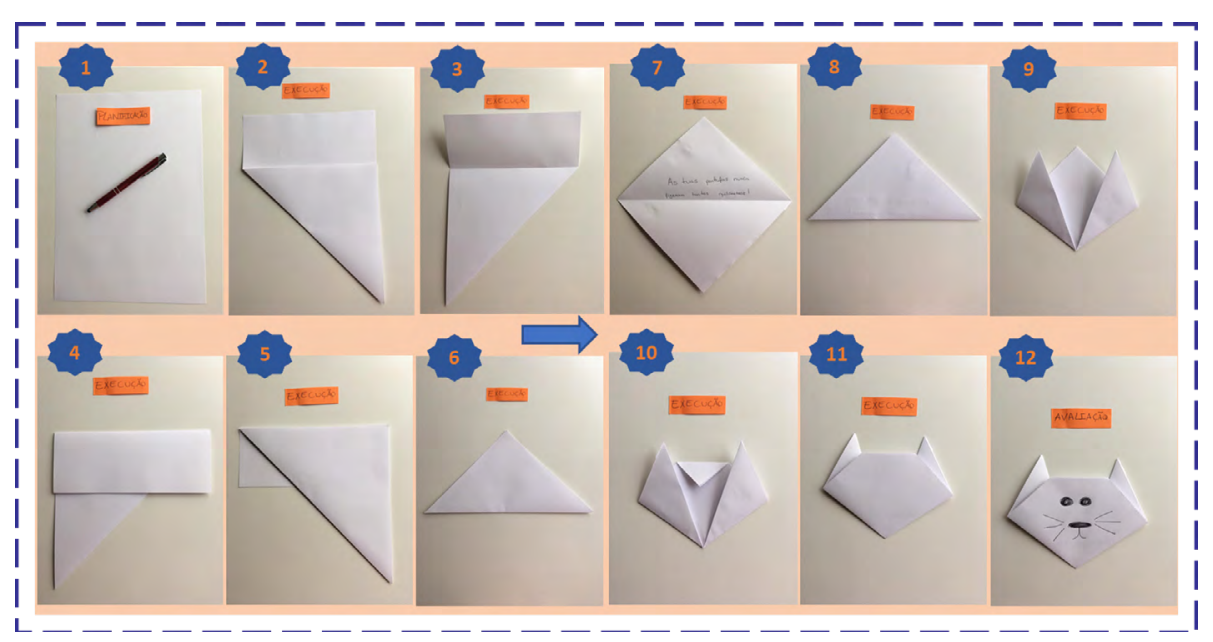

Figura 5. Exemplo de uma atividade do domínio "Ajudar alguém” (i.e., Construir um origami e escrever uma mensagem para animar alguém).

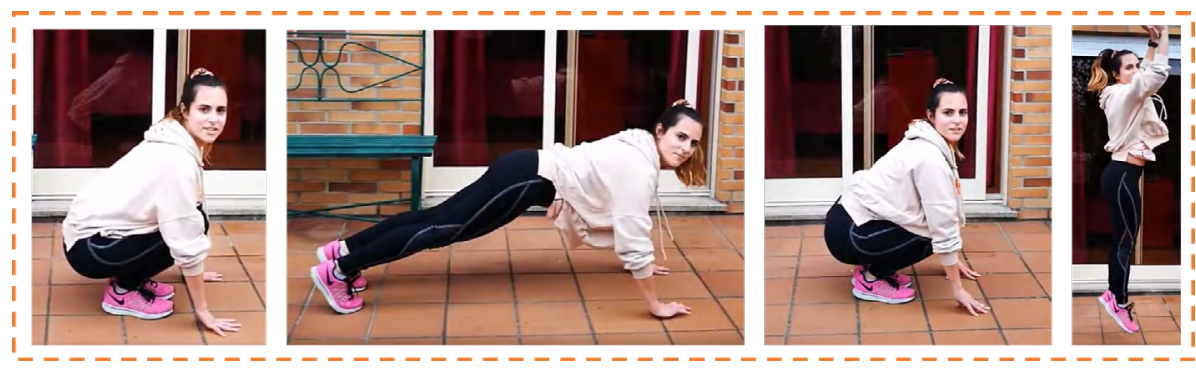

Figura 6. Exemplo de uma atividade do domínio "Lazer" (Exemplificação da fase de execução do PLEA).

Segundo, tal como referido anteriormente, estar em casa em confinamento juntamente com a família (e.g., pais, responsáveis legais) implicou a gestão de várias tarefas domésticas, havendo necessidade da colaboração de todos para manter o espaço organizado - facilitador da convivência harmoniosa - e disponível para a realização de tarefas de diferentes tipologias no mesmo local; por exemplo, em muitos casos os espaços reduzidos têm de ser multifuncionais (e.g., permitindo assistir às aulas na televisão, a aulas online, realizar reuniões de trabalho online, e fazer as refeições). Para além disso, diversos estudos indicam os benefícios de as crianças colaborarem nas tarefas domésticas, nomeadamente, na promoção da sua autoeficácia (i.e., crença de que é capaz de realizar uma tarefa), satisfação com a vida e comportamento pró-social (e.g., White et al., 2019). O domínio “Colaborar em casa” pretende responder a esta demanda. 
O terceiro domínio, "Ajudar alguém", pretende instigar a responsabilidade social. Estudos recentes indicam que os jovens que reportam mais responsabilidade social reportam envolver-se mais no distanciamento social, essencial para combater o contágio através do vírus (e.g., Oosterhoff et al., 2020).

O último domínio, "Lazer", foi criado com base na literatura que reporta os benefícios das atividades de lazer e exercício físico para o bem-estar e desenvolvimento positivo de crianças e jovens (e.g., Freire et al., 2016; Kuykendall et al., 2015). Este domínio assume uma importância acrescida em período de confinamento em casa durante a pandemia, uma vez que neste tempo aumenta o sedentarismo e os riscos associados (e.g., obesidade infantil; Dunton et al., 2020).

Para além das referidas atividades, foram ainda divulgados: vídeos com estórias (e.g., "Ali Babá e os 40 ladróes”) à luz da temática da autorregulação (e.g., Figura 7); reflexóes sobre a frase da semana (retirada do livro "Sarilhos do Amarelo"; e.g., Figura 8) e, ainda, dicas sobre temáticas variadas relacionados com o propósito do projeto (e.g. organização do estudo em casa, Figura 9), apresentadas por profissionais de diversas áreas. No final da semana, em cada domingo, foi publicado um pequeno vídeo onde a equipa celebrava o cumprimento de um objetivo, o fim de uma semana preenchida com propostas de trabalho autorregulatório em época de quarentena/isolamento social. De acordo com o ciclo autorregulatório (e.g., Zimmerman, 2002), celebrar pequenos objetivos ajuda a atingir o grande objetivo que é, neste caso, mitigar a propagação do vírus e salvar vidas, aproveitando a oportunidade para trabalhar competências de autorregulação da aprendizagem. Esta breve festa de objetivo, incita a renovar a força e a motivação para enfrentar mais uma semana.

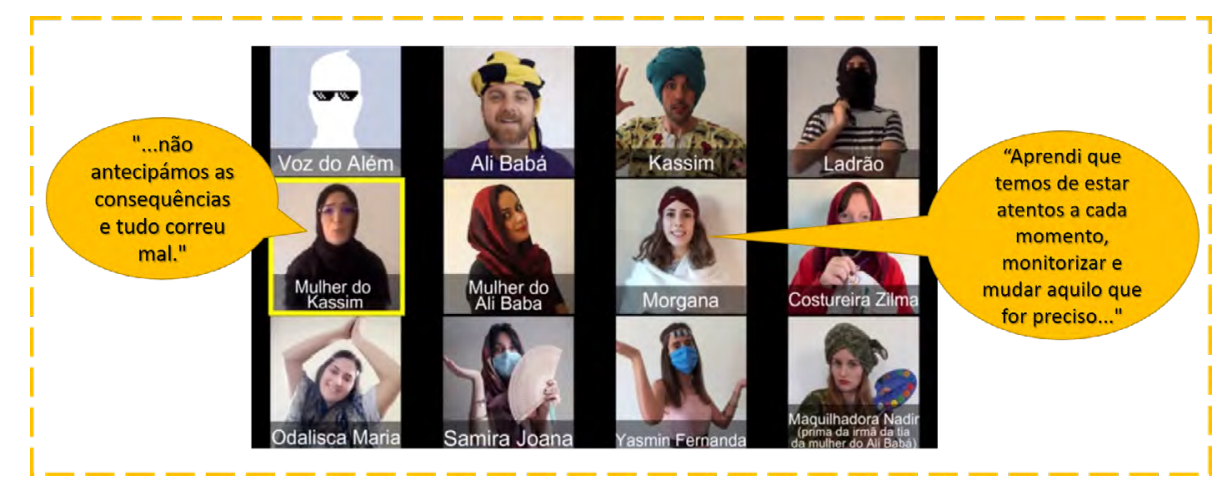

Figura 7. Frame do vídeo da estória "Ali Babá” com a reflexão das personagens (fase de avaliação). 


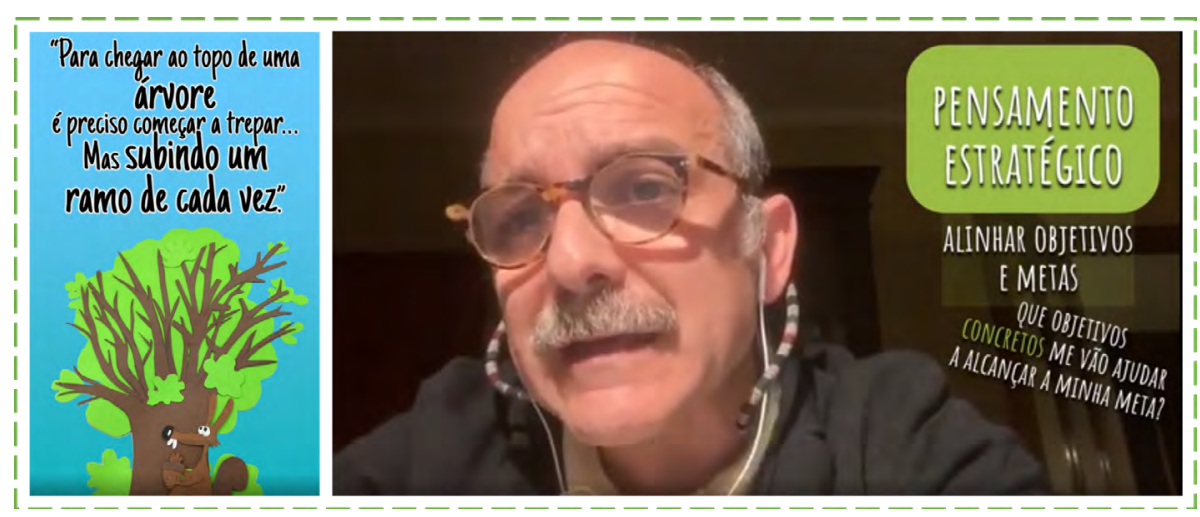

Figura 8. Frames do vídeo com a reflexão da frase da semana.

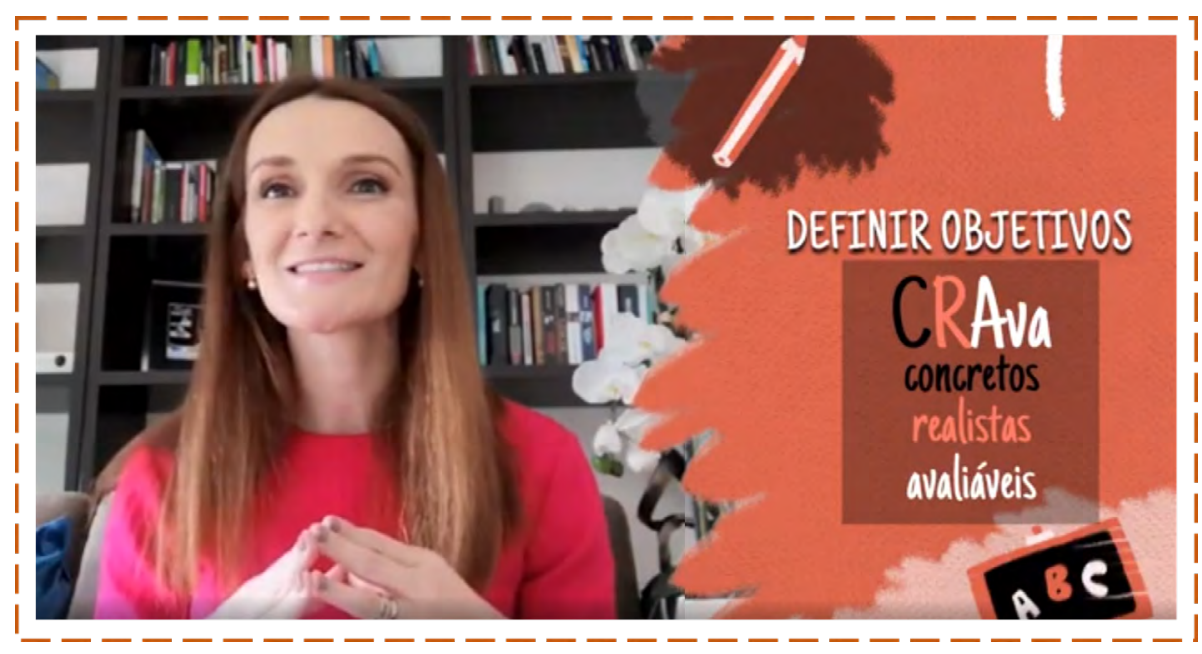

Figura 9. Frame do vídeo com dicas para a organização do estudo

Seguindo as recomendações da literatura do marketing digital, foi usada a ferramenta "histórias" das redes sociais (i.e. o conteúdo por fotos ou vídeo fica visível durante 24 horas de forma bastante acessível; Fonseca, 2019) com o objetivo de aumentar a interação com o público-alvo. Por exemplo, durante o dia a equipa colocou questões sobre as atividades propostas, soluçóes de todos os desafios ou, ainda, vídeos e imagens das atividades realizadas pelas crianças, partilhadas pelos seus pais ou tutores legais.

Com o início do 3o período, e tendo em conta a alteração de horários e o aumento de tarefas para o público-alvo do projeto (e.g., aulas na televisão, aulas síncronas com os professores, trabalho autónomo), foram realizadas modificações nas tarefas e horários propostos. Durante a semana, passaram a ser lançadas apenas duas atividades por 
dia, uma do domínio “Aprender algo" e outra do "Lazer" e um vídeo de "Bom Dia”. O vídeo "Bom Dia” foi publicado diariamente, durante a semana, no horário correspondente ao início das atividades letivas (8h30), com o propósito de incentivar as crianças para mais um dia de aulas na televisão. As atividades dos domínios “Aprender algo" e "Lazer" começaram a ser publicadas após o horário escolar. No fim de semana foram sugeridas quatro atividades por dia, duas do domínio "Colaborar em casa" e duas do domínio "Ajudar alguém”.

Para além das referidas alteraçóes, a tipologia da atividade de segunda-feira do domínio “Aprender algo" passou a integrar algumas tarefas que podiam ajudar as crianças a vivenciarem o 3o- período de uma forma mais ajustada (e.g., importância de ter um horário e explicação da elaboração do mesmo através do PLEA - Planificação, Execução e Avaliação). Todos os materiais do projeto foram criados para acompanhar as crianças e suas famílias até ao término do 3o período (fim de junho de 2020). Após este período, as páginas continuaram ativas, podendo os seguidores revisitar os seus conteúdos sempre que desejarem.

As estatísticas das redes sociais permitem monitorizar o alcance do projeto ( $\mathrm{Ta}$ bela 1). Até à submissão do presente capítulo, contabilizou-se 5931 seguidores nas páginas do Facebook ${ }^{\circledR}$ e Instagram ${ }^{\circledR}$, sendo a maioria do sexo feminino e da regiáo Norte. 
Tabela 1. Métricas fornecidas pelas redes sociais Facebook e Instagram.

\begin{tabular}{|c|c|c|c|}
\hline \multicolumn{2}{|c|}{ Métricas/Rede social } & Facebook & Instagram \\
\hline \multicolumn{2}{|c|}{ Seguidores } & 4692 & 1239 \\
\hline \multicolumn{2}{|c|}{ Alcance } & 4400 & 1000 \\
\hline \multicolumn{2}{|c|}{ Género } & $\begin{array}{l}\text { Feminino: } 84 \% \\
\text { Masculino: } 15 \% \\
\text { Omisso: } 1 \%\end{array}$ & $\begin{array}{l}\text { Feminino: } 84 \% \\
\text { Masculino: } 16 \%\end{array}$ \\
\hline \multicolumn{2}{|c|}{ Idade } & $35-44$ anos & $25-44$ anos \\
\hline \multicolumn{2}{|c|}{ Top 5 cidades } & $\begin{array}{l}\text { Braga, Porto, Guimarães, Lisboa, } \\
\text { Bragança }\end{array}$ & $\begin{array}{l}\text { Braga, Porto, Lisboa, Guimarães, } \\
\text { Bragança }\end{array}$ \\
\hline \multicolumn{2}{|c|}{ Top 5 países } & $\begin{array}{l}\text { Portugal, Brasil, Suíça, França, } \\
\text { Espanha }\end{array}$ & $\begin{array}{l}\text { Portugal, Brasil, Suíça, Espanha, } \\
\text { Reino Unido }\end{array}$ \\
\hline \multirow{5}{*}{ 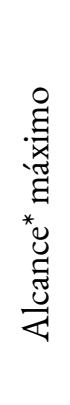 } & Vídeos-resumo & 29800 & Dados indisponíveis \\
\hline & Atividades sugeridas & Dados indisponíveis & Dados indisponíveis \\
\hline & Estória da Semana & 17400 & 683 \\
\hline & Frase da Semana & 5900 & 686 \\
\hline & Dicas da Semana & 3900 & 390 \\
\hline
\end{tabular}

Nota. *Número de pessoas que visualiza o conteúdo disponibilizado na rede social, mesmo que não seja seguidor da página (dados consultados a 08.06.2020).

Paralelamente às atividades do "COVID-19 em Sarilhos", os implementadores do "Sarilhos do Amarelo" em diferentes zonas do país desenvolveram, com o apoio do GUIA, reajustes à intervenção considerando a nova situação, as necessidades e os recursos existentes. Como resultado, surgiram propostas em modalidade online e offline (Figura 1). Esta última para responder às famílias sem acesso à internet. A secção seguinte descreve sucintamente cada uma das propostas. 


\section{“SARILHOS DO AMARELO” EM TEMPO DE PANDEMIA: MODALIDA- DES ONLINE E OFFLINE}

\section{Modalidades online}

Tendo em atenção a diversidade de realidades e recursos existentes em cada contexto, foram desenvolvidas diferentes modalidades de intervenção online. Estas surgiram posteriormente, mais concretamente entre a 2a e 9a semana de confinamento, e basearam-se em variadas ferramentas digitais.

\section{- Sessões síncronas}

Resposta que surgiu como a adaptação mais próxima às sessões presenciais. Ocorreu com uma periodicidade (semanal ou quinzenal), duração (entre 30 a 75 minutos) e formato (estrutura das sessóes) diferentes de implementador para implementador, de acordo com a disponibilidades dos alunos, dos implementadores e dos recursos existentes. O formato seguido nas sessões foi variado: em algumas instituições, as sessões síncronas replicaram o protocolo seguido nas sessões presenciais (saudação, organizador prévio, leitura do(s) capítulo(s), reflexão da estória, atividade de consolidação e lição final); noutras instituições o protocolo foi alterado. Alguns implementadores optaram por solicitar que a leitura do capítulo fosse realizada com os pais (fora do horário das aulas síncronas) ou com a professora titular de turma na aula síncrona de português. Nestas sessões o vídeo-resumo do capítulo (disponibilizado na página do "COVID-19 em Sarilhos”) foi visualizado pelos alunos e o seu conteúdo foi explorado brevemente. As atividades de consolidação também foram reorganizadas, sendo que algumas foram realizadas de forma síncrona e outras assíncrona. A figura 10 apresenta um exemplo das atividades construídas pelo GUIA para cada um dos capítulos. Uma das entidades parceiras criou um site com atividades interativas em formato de "Jogo da Glória” com perguntas exploratórias dos vários capítulos. 


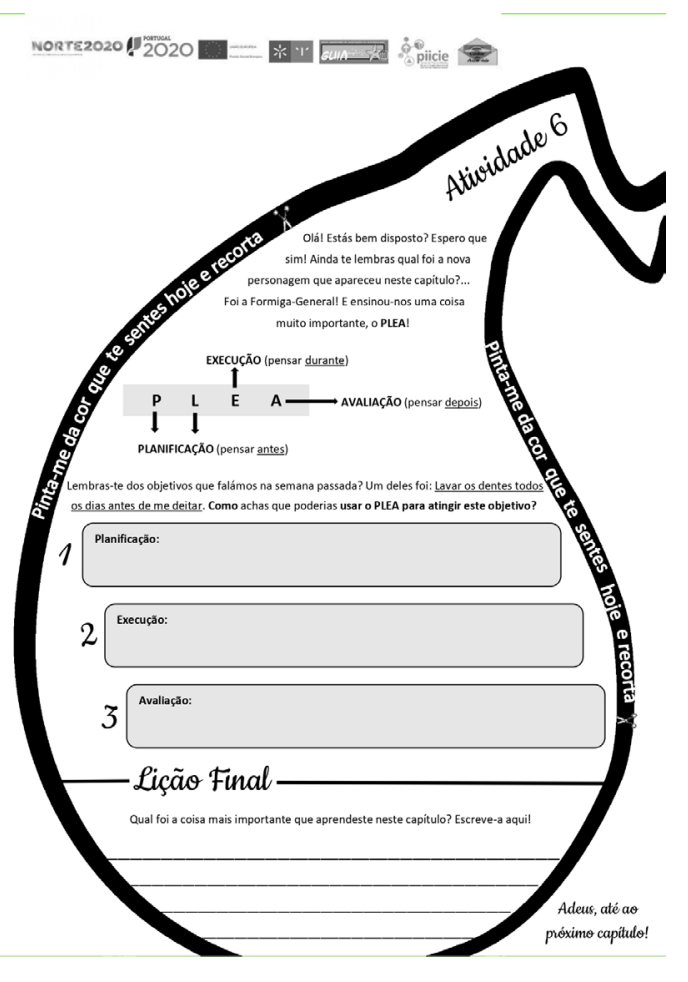

Figura 10. Exemplo de atividade.

\section{- Blogue}

Modelo de implementação do projeto "Sarilhos do Amarelo" dinamizado através de um blogue. Ao longo de cada semana, as crianças receberam, via e-mail, um guiáo relativo à sessão da semana com o(s) objetivo(s) a trabalhar, alguns excertos do livro "Sarilhos do Amarelo" e questões de reflexão. Para além disto, o guião direciona as crianças para um blogue. Nesta ferramenta foi disponibilizado um áudio com a leitura dramatizada de cada capítulo, um vídeo que inclui uma reflexão sobre as questóes colocadas no guião e uma proposta de atividade de consolidação dos conteúdos abordados nos capítulos.

\section{- Vídeos}

Intervenção adotada por diferentes implementadores que se baseou na criação de vídeos semanais focados na leitura dos capítulos da estória ferramenta "Sarilhos do Amarelo" e no desenvolvimento de atividades e/ou questóes de natureza reflexiva com o propósito de promover o pensamento e consolidação do conteúdo de cada capítulo. Os vídeos e atividades foram partilhados pelos implementadores através de diversas plataformas, dependendo de cada contexto (e.g., Facebook ${ }^{\circledR}$, Whats $A p p{ }^{\circledR}$, email, Microsoft Teams $\left.{ }^{\circledR}\right)$. Por sua vez, a devolução da resposta a estas atividades foi realizada em diversos moldes, dependendo da instituição, podendo esta ser escrita ou por vídeo. 


\section{- Google Forms ${ }^{\circledR}$}

Formato de intervenção que incluiu a disponibilização do livro "Sarilhos do Amarelo", em formato digital, a todas as crianças para que estas pudessem realizar uma leitura autónoma do(s) capítulo(s) destinado(s) a cada semana. Os implementadores tinham como propósito promover a envolvência da família e, por isso, sugeriram que os capítulos do livro fossem lidos em atividade familiar. Após a leitura, as crianças acediam a um link, no Google forms ${ }^{\circledR}$, onde encontravam questôes referentes ao(s) capítulo(s) que tinham lido (algumas questóes exploratórias e outras de natureza reflexiva). Para além destas questóes, as crianças realizavam uma atividade de consolidação dos conteúdos aprendidos, através da mesma ferramenta, Google Forms ${ }^{\circledR}$.

\section{Modalidades offline}

A dificuldade de acesso à Internet e/ou dispositivos eletrónicos, acrescida de dificuldades de manuseamento/utilização dos mesmos, por um elevado número de crianças ao longo do país, incitou a criação de respostas que tivessem em atenção esta realidade. Paralelamente ao desenvolvimento das páginas "COVID-19 em Sarilhos", o GUIA criou as Cartas do Arco-Íris. Posteriormente, um dos implementadores do "Sarilhos do Amarelo" avançou com a leitura e dramatização da narrativa na rádio local. Estas respostas estão alinhadas com a mensagem da narrativa de que todos são importantes e ninguém pode ser deixado para trás. Este foi o motivo que levou as cores a partir à procura do seu amigo Amarelo, e o GUIA e implementadores do "Sarilhos do Amarelo" a procuraram respostas alternativas para não deixarem para trás crianças e famílias sem acesso à internet ou a dispositivos eletrónicos.

\section{- “Cartas do Arco-íris “}

Resposta desenvolvida a partir da adaptação dos conteúdos das redes sociais do "COVID-19 em Sarilhos” para o papel. Semanalmente, estas cartas foram construídas pelo GUIA e enviadas às diferentes entidades parceiras que as deviam imprimir e fazer chegar às crianças, por exemplo, através das juntas de freguesia ou professores. A figura 11 apresenta um exemplo de uma das cartas enviadas.

Em cada uma das cartas, o protagonista é uma das Cores do Arco-íris (e.g., o Azul), sendo diferente de semana para semana. Cada carta é constituída por três atividades de um dos domínios "Aprender algo", "Colaborar em casa”, "Ajudar alguém” e 
"Lazer". Quinzenalmente, foi também apresentada a reflexão de uma frase da semana, retirada do "Sarilhos do Amarelo". De forma a tornar estes materiais visualmente mais atrativas para as crianças, todas as cartas apesentam o formato de gota (inspirada nas gotas do projeto "COVID-19 em Sarilhos"). Cada gota pode ser colorida (com a cor do remetente da carta) e recortada pela criança; no final, a coleção das gotas das atividades coloridas e recortadas, permite formar um Arco-íris.

Juntamente com a carta 1, foi enviada uma "Carta Inicial", com o objetivo de apresentar e explicar às famílias o funcionamento do projeto nesta modalidade. Para além das 12 "Cartas do Arco-Íris" e da "Carta Inicial”, foi criada uma "carta extra” denominada "Dicas do Arco-íris", que inclui sugestôes que permitem ajudar as crianças a vivenciar o 3o período de uma forma mais ajustada (e.g., importância de ter um horário e a explicação da elaboração do mesmo através do PLEA), à semelhança do conteúdo publicado nas páginas "COVID-19 em Sarilhos”. Nas cartas seguintes às que apresentam desafios e frases para reflexão é sempre providenciado feedback.

As "Cartas do Arco-íris" foram construídas para acompanhar as crianças e suas famílias até ao término do 3o período.

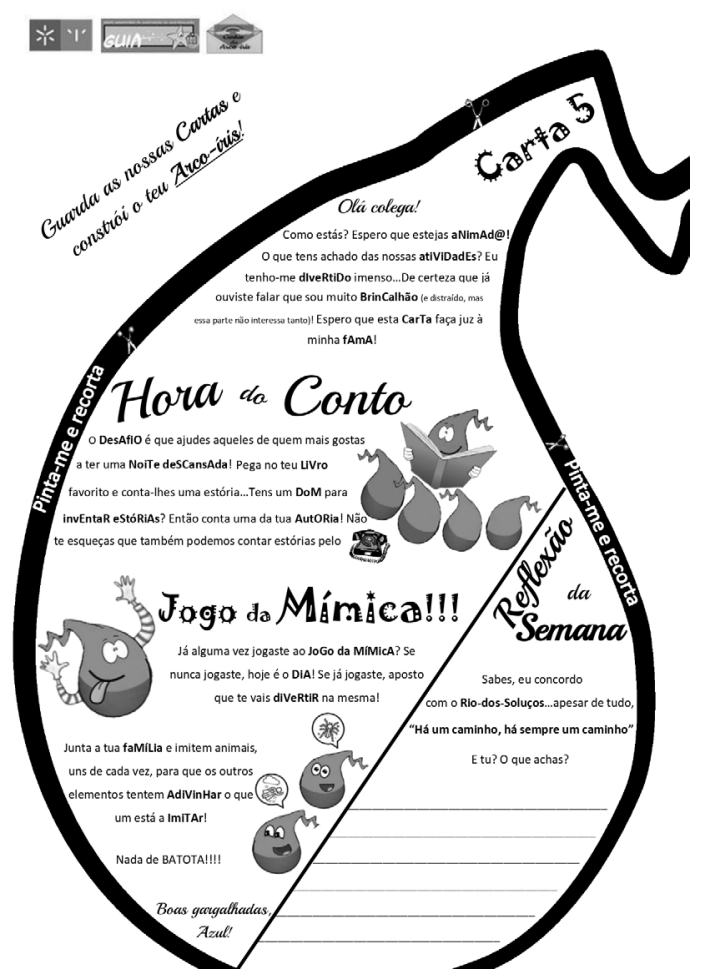

Figura 11. Exemplo de uma carta do Arco-íris. 


\section{- Leitura dramatizada na rádio e atividade em papel}

Este formato tem por base a leitura dramatizada, na rádio local, dos capítulos do livro "Sarilhos do Amarelo", acrescida de um conjunto de atividades em papel. Em cada semana as crianças receberam em casa um guião impresso que incluiu: o(s) objetivo(s) a trabalhar na sessão da semana, alguns excertos do livro, questóes de reflexão e informação sobre a data e hora de emissão da leitura dos capítulos. Para além do guião foi-lhes disponibilizada uma ficha com a atividade de consolidação e algumas reflexôes sobre as questôes colocadas no guião.

\section{LIÇÕES APRENDIDAS E SUGESTÕES PARA O FUTURO}

A COVID-19 invadiu a vida de todos, alterando as rotinas e dinâmicas habituais. Neste contexto, os indivíduos com competências autorregulatórias frágeis são mais facilmente suscetíveis à influência da desordem exterior (e.g., espaço) e interior (e.g., emoçôes como a ansiedade, pensamentos negativos). Esta desordem, se descontrolada, pode gerar disfunções nos processos autorregulatórios, interferindo negativamente no desempenho dos papéis dos membros do agregado familiar e da saúde familiar como um todo.

Com o projeto descrito pretende-se contrariar este cenário. É a COVID-19 que fica, ficou, em "sarilhos” e não as famílias, pois o objetivo é instigar o empoderamento das crianças e dos adultos, através da aprendizagem e treino de competências autorregulatórias. Para tal, todos os materiais desenvolvidos estão ancorados no quadro teórico da autorregulação (e.g., Rosário et al., 2007b; Zimmerman, 2002) e organizados em quatro domínios essenciais para promover a aprendizagem e o bem-estar das famílias em período de pandemia (Freire et al., 2016; Dunton et al., 2020; Oosterhoff et al., 2020; White et al., 2019; Zhou et al., 2020).

Este é um projeto recém-nascido, contudo o processo do seu desenvolvimento e o feedback recebido dos seus seguidores têm oferecido oportunidades múltiplas de aprendizagem. De seguida são apresentadas algumas lições aprendidas com a experiência do projeto "COVID-19 em Sarilhos": 
- Criatividade e sensibilidade. A fase em que as famílias se encontravam quando lançámos o projeto, exigia respostas criativas, mas também sensibilidade para a forma como os desafios diários poderiam ser recebidos. Neste sentido, foi fundamental monitorizar como os conteúdos e atividades oferecidas estavam a ser recebidos. Queríamos garantir que as atividades contribuíam para as famílias regularem e ajustarem as rotinas à nova realidade que viviam, não as sobrecarregando. As famílias, sobretudo nas primeiras semanas, estavam sobrecarregadas de propostas adhoc que chegavam pelos media (e.g., desportivas, instrutivas, médicas); esta dose desproporcional de propostas, acrescida às novas tarefas que a família tinha entre mãos poderia, contrariamente ao pretendido, desmobilizar. A nossa proposta era integrada, guiada teoricamente e consistente ao longo das 15 semanas; mas para além do conteúdo, cuidámos diariamente o impacto do que apresentámos às famílias e mudámos (e.g., frequência das atividades, tipo de atividades, horários de lançamento) sempre que considerámos ajustado.

- Não basta oferecer uma resposta, a resposta tem que ser flexível. A flexibilidade pautou a resposta às necessidades nas diferentes fases da quarentena: do estado de emergência, início das aulas na televisão até ao processo de desconfinamento gradual.

- Estado de emergência - responder à necessidade de desenvolver atividades com crianças em fase de confinamento. Neste sentido, foi desenhado e disponibilizado um menu diversificado de atividades diárias, separado por domínios, oferecendo a possibilidade de escolha por parte das famílias e crianças.

- Aulas na televisão - a transição para a fase de aulas na televisão ofereceu novos desafios às famílias. Por um lado, a mudança de formato de atividade letiva, i.e., em casa, com os pais em teletrabalho ou preocupados com o futuro profissional, exigindo de cada aluno/a controlo sobre o seu próprio processo de aprendizagem. Após analisado o novo cenário e as necessidades emergentes, tornou-se premente ajustar a grelha de conteúdos e horários, tal como descrito anteriormente (i.e., diminuição do número de atividades durante a semana, alteração da distribuição da tipologia de atividades durante a semana e ao fim de semana, reforço de atividades e rubricas com 
o propósito de informar e capacitar os alunos com estratégias que auxiliassem o seu estudo em casa).

- Desconfinamento - voltar a sair de casa também ofereceu diversos desafios. Nesta etapa, foi fundamental introduzir atividades lúdicas que reforçassem, com intencionalidade, as medidas essenciais ao regresso à rua em segurança. Para tal, foram desenvolvidas atividades relacionadas com o uso de máscara e desinfeção de objetos pessoais (e.g., sapatilhas).

- Integrar e ajustar uma intervenção educativa às redes sociais sem perder intencionalidade e propósito, exige recolha constante de feedback e reflexão de uma equipa multidisciplinar (e.g., psicólogos, ilustradores, designers multimédia).

- O alcance e a educação nas redes sociais. Apesar do longo alcance das páginas do "COVID-19 em Sarilhos", é importante sensibilizar para este formato na intervenção educativa e diversificar e potenciar as possibilidades de interação com o público-alvo (e.g., utilização da ferramenta "histórias" mencionada anteriormente).

Como referido anteriormente, paralelamente ao "COVID-19 em Sarilhos", os implementadores do "Sarilhos do Amarelo" desenvolveram, com o apoio do GUIA, reajustes à intervenção para poderem dar continuidade ao projeto durante o estado de emergência e calamidade. Do feedback recebido dos implementadores do projeto "Sarilhos do Amarelo", nas modalidades online e offline, destacamos as seguintes lições aprendidas:

- Resistência substituída pela persistência. Apesar da resistência inicial dos implementadores em dar continuidade ao projeto face ao encerramento das escolas, os implementadores abraçaram o desafio de encontrar novas formas de resposta, considerando os recursos existentes e dando asas à sua criatividade.

- Crianças preferem a modalidade presencial. Apesar do feedback ser bastante positivo em todas as modalidades alternativas do projeto, as crianças reportam que preferem as sessóes presenciais do projeto. A presencialidade permite-lhes interagir com os colegas e com o implementador do projeto (e.g., professor, psicólogo). 
- Limitação do formato a distância. Todos os implementadores reportaram a dificuldade de promover os processos metacognitivos nos novos formatos em que não há possibilidade de discutir interativamente e de forma próxima com as crianças.

- Sobrecarga de tarefas escolares. As crianças reportaram uma carga elevada de trabalho escolar, estando menos disponíveis para as atividades propostas no âmbito do projeto.

- Heterogeneidade no envolvimento parental. Uma parte dos pais/responsáveis legais das crianças tende a centrar-se exclusivamente nos conteúdos escolares, não aderindo ao projeto; a este e outros que não estritamente focados na instrução. Por outro lado, outros pais/responsáveis legais das crianças envolveram-se ativamente no projeto, apoiando e/ou participando nas atividades do projeto.

Considerando as lições aprendidas, no futuro seria importante:

- Planificar a continuidade dos projetos educativos, este em particular, no próximo ano letivo (2020/2021). Dada a imprevisibilidade que caracteriza a atividade deste vírus e também a sua intensa virulência, não é possível descartar uma nova vaga no próximo outono/inverno; neste sentido, é importante avaliar a eficácia das respostas educativas oferecidas este ano letivo e planificar antecipadamente as novas respostas educativas.

- Calibrar a carga de trabalho escolar das crianças. Não é sensato esperar que os alunos confinados em casa, longe do apoio direto dos professores, desenvolvam a quantidade de trabalho que desenvolveriam numa situação de presencialidade. $\mathrm{O}$ confinamento causa sobrecarga nos alunos e nas próprias famílias, repercutindo-se na qualidade das aprendizagens, convivência familiar e na disponibilidade para participarem noutras iniciativas promotoras do seu desenvolvimento integral. Expectativas irrealistas por parte de professores e pais sobre o trabalho das crianças não facilitam o desenvolvimento de um trabalho ajustado e de qualidade.

- É necessário que as crianças desenvolvam competências transversais e não aprendam apenas os conteúdos programáticos. Por exemplo, na China, o semestre da primavera foi adiado e, nos primeiros tempos, foi providenciado 
apoio para que as crianças pudessem desenvolver autonomia no estudo (Zhou et al., 2020).

\section{CONSIDERAÇÕES FINAIS}

A pandemia COVID-19 trouxe consigo desafios e muita incerteza. O projeto aqui descrito (e suas ramificaçôes) abraçou estes dois fatores como uma oportunidade. Uma oportunidade para inovar, construindo novas respostas a partir da investigação, e ajudar as famílias durante o estado de emergência e calamidade. Para isso aliámos o conhecimento científico aos meios tecnológicos e planificámos uma resposta ancorada no quadro teórico da autorregulação. Em diversos momentos no decorrer do projeto foi necessário efetuar reajustes e iniciar respostas alternativas (e.g., Cartas do Arco-íris); o que só foi possível a partir da constante monitorização do processo. Por fim, o projeto será avaliado a partir de diferentes métodos e fontes de informação, o resultado será essencial para preparar a próxima fase. A missão continuará, ainda que em moldes, porventura, diferenciados, mas sempre com o entusiasmo de cumprir os objetivos propostos.

"Quando alcançamos algo difícil, a alegria da conquista é maior."

(Pássaro-Maestro, Sarilhos do Amarelo, p. 70)

\section{AGRADECIMENTOS}

Agradecimento a todos os colaboradores do Projeto "COVID-19 em Sarilhos", que trabalharam na construção de materiais, dinamização e monitorização das redes sociais.

Equipa COVID-19 em Sarilhos: Ana Barbosa, Ana Guimarães, André Oliveira, Armanda Pereira, Beatriz Pereira, Bruno Rabaçal, Camila Aguiar, Catarina Vilas, Cátia Silva, Clara Vieira, Daniela Rosendo, David Santos, Dulce Lopes, Gabriela Figueiredo, Gil Dias, Hélder Oliveira, Joana Araújo, Juliana Martins, Patrícia Sousa, Pedro Rosário, Raquel Azevedo, Rita Nunes, Sandra Mesquita, Sara Miranda, Sara Teixeira, Sofia Vidal e Tânia Moreira. 
Ao Ângelo Costa pela tradução para Língua Gestual Portuguesa da estória "As Fadas”.

A todos os que participaram na dramatização das estórias da semana.

Participaçóes nas Dicas da Semana: Associação Paralisia Cerebral de Braga (Departamentos de Fisioterapia, Terapia Ocupacional, Terapia da Fala, Psicologia e Ação Social), Cátia Silva, Eva Fernandes, Íris Oliveira, João Tiago Oliveira, Sofia Ramalho e Tầnia Nunes.

Empresa I'M COACH PERSONAL TRAINING pelos vídeos do treino.

À Sara Perestrelo Pinto e à Bárbara Couto pelos vídeos de Yoga.

Ao $\mathrm{ABC}$ de Castelo Branco pelo vídeo de treino.

À Radio Clube de Monsanto pela emissão da leitura dramatizada do livro "Sarilhos do Amarelo".

A todos os professores, psicólogos e outros técnicos ou entidades que divulgaram e/ou tornaram possível a implementação das diferentes modalidades online e offline de intervenção.

A todas as crianças e Encarregados de Educação que divulgaram e participaram nas diferentes modalidades de intervenção apresentadas.

\section{REFERÊNCIAS BIBLIOGRÁFICAS}

Bandura, A. (2006). Toward a Psychology of Human Agency. Perspectives on Psychological Science, 1(2), 164180. https://doi.org/10.1111/j.1745-6916.2006.00011.x.

Dunton, G., Do, B., \& Wang, S. (2020). Early Effects of the COVID-19 Pandemic on Physical Activity and Sedentary Behavior in U.S. Children. Cambridge Open Engage. https://doi.org/10.33774/coe-2020-q6pz0. Fonseca, C. (2019). Amplify Your Impact: The Insta-Story: A New Frontier for Marking and Engagement at the Sonoma State University Library. Reference \& User Services Quarterly, 58(4), 219-226. https://doi. org/10.5860/rusq.58.4.7148.

Freire, T., Tavares, D., Silva, E., \& Teixeira, A. (2016). Flow, Leisure, and Positive Youth Development. In L. Harmat, F. Ørsted Andersen, F. Ullén, J. Wright, G. Sadlo (Eds.), Flow Experience: Empirical Research and Applications, (pp.163-178). Springer. https://doi.org/10.1007/978-3-319-28634-1_11.

Högemann, J. (2011). Promoção de competências de autorregulação na escrita: um estudo no 1o ciclo do ensino 
básico (Dissertação de Mestrado não pulicada). Universidade do Minho, Braga.

Högemann, J. (2016). Promoģão de competências de autorregulação na escrita: Um estudo com alunos do 4o ano do Ensino Básico (Dissertação de Doutoramento não publicada). Universidade do Minho, Braga.

Högemann, J., Rosário, P., Núñez, J. C., Rodríguez, C., \& Valle, A. (2017). Promoting self-regulatory skills in writing using a story-toll. In R. Fidalgo, K.R. Harris, \& M. Braaksma (Eds.), Studies in Writing. Design Principles for teaching effective writing: Theoretical and empirical grounded principles (pp. 189-221) Leiden, NL: Brill Editions.

Kuykendall, L., Tay, L., \& Ng, V. (2015). Leisure engagement and subjective well-being: A meta-analysis. Psychological bulletin, 141(2), 364-403. https://doi.org/10.1037/a0038508.

Fernandes, O. (2009). Estórias como ferramentas para promover competências de auto-regulação: Um estudo no $4 \div$ ano de escolaridade (Dissertação de Mestrado não publicada). Universidade do Minho, Braga.

Oosterhoff, B., Palmer, C. A., Wilson, J., \& Shook, N. (2020). Adolescents' Motivations to Engage in Social Distancing during the COVID-19 Pandemic: Associations with Mental and Social Health. Journal of Adolescent Health, xxx, 1-7. https://doi.org/10.1016/j.jadohealth.2020.05.004.

Rosário, P., Núñez, J. C., \& González-Pienda,J. A. (2007a). Auto-regulação em crianças sub-10: Projeto Sarilhos do Amarelo. Porto Editora.

Rosário, P., Núñez, J. C., \& González-Pienda, J. A. (2007b). Sarilhos do Amarelo. Porto Editora.

Rosário, P. \& Polydoro, S. (2014). Capitanear o Aprender: Promoção da autorregulação da aprendizagem no contexto escolar (1aed.). Casa do Psicólogo.

Rosário, P., Núñez, J. C., Vallejo, G., Cunha, J., Azevedo, R., Pereira, R., Nunes, A. R., Fuentes, S., \& Moreira, T. (2016). Promoting Gypsy children school engagement: A story-tool project to enhance self-regulated learning. Comtemporary Educational Psychology, 47, 84-94. https://doi.org/10.1016/j.cedpsych.2015.11.005.

Rosário, P., Núñez,J. C., Rodríguez, C., Cerezo, R., Fernández, E., Tuero, E., \& Högemann,J. (2017). Analysis of instructional programs for improving self-regulated learning SRL through written text. In R. Fidalgo, K. Harris, \& M. Braaksma (Eds.), Design Principles for Teaching Effective Writing (pp. 201-231). Brill Editions. https://doi.org/10.1163/9789004270480 010.

White, E. M., DeBoer, M. D., \& Scharf, R. J. (2019). Associations Between Household Chores and Childhood Self-Competency. Journal of developmental and behavioral pediatrics: JDBP, 4O(3), 176-182. https://doi. org/10.1097/DBP.0000000000000637.

Zimmerman, B. J. (2002). Becoming a self-regulated learner: An overview. Theory into practice, 41(2), 64-70. https://doi.org/10.1207/s15430421tip4102_2.

Zhou, L., Wu, S., Zhou, M., \& Li, F. (2020). 'School's Out, But Class' On', The Largest Online Education in the World Today: Taking China's Practical Exploration During The COVID-19 Epidemic Prevention and Control As an Example. Best Evid Chin Edu 2020, 4(2), 501-519. http://dx.doi.org/10.2139/ssrn.3555520. 